\title{
Fast furfural formation from xylose using solid super acid catalysts assisted by a microwave reactor
}

\author{
Gerardo Gómez Millán ${ }^{*[a, b]}$, Zouhair El Assal|[c], Kaarlo Nieminen ${ }^{[a]}$, Sanna Hellsten ${ }^{[a]}$, Jordi Llorca ${ }^{[b]}$, \\ Herbert Sixta*[a]
}

[a] G. Gómez Millán, DSc. K. Nieminen, DSc. S. Héllsten, Prof. H. Sixta

Department of Bioproducts and Biosystems

Aalto University

Vuorimiehentie 1, 02150 Espoo (Finland)

*E-mail: gerardo.gomezmillan@aalto.fi

herbert.sixta@aalto.fi

[b] G. Gómez Millán, Prof. J. Llorca

Department of Chemical Engineering, Institute of Energy Technologies and Barcelona Research Center in Multiscale Science and Engineering

Universitat Politècnica de Catalunya

Eduard Maristany 10-14, 08019 Barcelona (Spain)

[c] Z. El Assal

Department of Environmental and Chemical Engineering, Faculty of Technology

University of Oulu

P.O. Box 4300, 90014 Oulu (Finland)

\begin{abstract}
The production of furfural (FUR) from xylose was carried out using sulfated zirconia (SZ) on cordierite, alumina on cordierite and commercially-available polymeric solid catalysts (Amberlyst DT and Nafion NR40) to provide insights into the reaction pathways and kinetics for the dehydration of xylose in aqueous phase. Experiments conducted at three temperatures were investigated $\left(170,190\right.$ and $\left.210{ }^{\circ} \mathrm{C}\right)$ in a stirred microwaveassisted batch reactor, which established the optimal conditions to obtain the highest FUR yield as well as extensive and fast xylose conversion. The maximum FUR yields obtained from xylose were 41 mol\% when using SZ on cordierite in $2 \mathrm{~min}\left(\right.$ at $210^{\circ} \mathrm{C}$ ), $43 \mathrm{~mol} \%$ when using alumina on cordierite in $30 \mathrm{~min}\left(\right.$ at $210^{\circ} \mathrm{C}$ ) and $48 \mathrm{~mol} \%$ for an auto-catalyzed system in $60 \mathrm{~min}\left(\right.$ at $210^{\circ} \mathrm{C}$ ). Based on the experimental results, a reaction mechanism was proposed considering the formation of an intermediate from xylose when solid acid catalysts were added. After five reusability cycles using SZ, this catalyst can be regenerated with a similar performance and similar FUR yield on the $6^{\text {th }}$ cycle.
\end{abstract}

Keywords: alumina; Amberlyst DT; furfural; Nafion NR40; sulfated zirconia; xylose 


\section{Introduction}

Furfural (furan-2-carbaldehyde, FUR), is the dehydration product of xylose and other pentoses, $\mathrm{C}_{5}$-sugars typically found in hemicellulose in lignocellulosic biomass. A wide range of FUR derivatives with high potential for applications has been identified. FUR is considered a selective solvent for organic compounds and serves as a building block for its hydrogenation to furfuryl alcohol, for components of P-series fuels or liquid alkanes, and in the manufacture of foundry resins [1-3]. Tetrahydrofuran and tetrahydrofurfuryl alcohol are the other two main chemicals obtained from FUR that have wide applications in the chemical industry. The rest of the FUR is employed in oil refining, pharmaceutical, plastics and agrochemical industries (as fungicide and nematicide) [4]. Although xylan and xylose have not yet been fully utilized in the paper industry, a significant amount of xylose, from the hydrolysis of woody biomass, is mixed with lignin-derived compounds and burned to provide process heat [5]. Therefore, valorization of these compounds offers a new economic approach for new ideas and new markets.

The commercial process for the production of FUR involves several environmental issues, such as toxic effluents derived from mineral acids (sulfuric or phosphoric acid) at temperatures of approximately $200{ }^{\circ} \mathrm{C}$ and the consumption of high stripping-steam to FUR ratios, especially related to important energy and environmental concerns regarding the fuel employed to generate the steam. Homogeneous acids (in the form of dilute aqueous solutions) achieve a one-step hemicellulose deconstruction and xylose dehydration in the same reactor. However, the utilization of these corrosive homogeneous mineral acids leads to challenges in product separation, equipment corrosion, mineral acid loss, high amounts of acidic and toxic waste, as well as a significant amount of side reactions that limit FUR yields to ca. 50\% [6]. New methodologies based on the use of easily-separable solid catalysts including zeolites [7-14], aluminosilicates supported with metals [15], modified silica [16-23], alumina [12], zirconia $[12,24]$ solid acids like layered zeolite Nu-6 [25], sulfonated graphenes [26], heteropolyacids [2729], coated activated carbon [30] and resins [20,31,32] to yield xylose dehydration are currently being explored to improve FUR yields in a much more environmentally friendly and efficient industrial process. Nevertheless, the 
utilization of solid acid catalysts usually requires from two [12] up to twenty hours [21, 23, 27-29, 33] to reach high FUR yields in aqueous phase.

The ongoing discussion of the proper reaction mechanisms of FUR formation has generated proposals for different formation pathways under homogeneous and heterogeneous catalysis. O'Neill and co-workers claim that xylose could be isomerized to lyxose via adsorption onto the acidic active sites of ZSM-5 zeolite [8]. These steps would occur through the formation of the linear open chain of xylose molecules caused by the acidcatalyzed hydrolysis. On the other hand, Verma et al [34] proposed a mechanism via the formation of 2,5anhydoxylose furanose cyclic intermediate using a sulfonated graphitic carbon nitride. Xylulose, a xylose isomer, has been under discussion as possible intermediate on FUR formation $[35,36]$. However, there is no conclusive information on either pathway.

In this work, we aimed to employ solid acid catalysts for the dehydration of xylose to produce FUR in short times. In addition, the kinetic model for this reaction was further investigated and a reaction mechanism is proposed for heterogeneously catalyzed systems. Due to their hydrothermal stability and high acid site density [37], solid acid catalysts were developed $\left(\mathrm{Al}_{2} \mathrm{O}_{3}\right.$ and $\mathrm{ZrO}_{2}\left(\mathrm{SO}_{4}{ }^{2-}\right)$ on cordierite $)$ and compared to commercially available polymeric resins (Amberlyst DT and Nafion NR40). Their hydrothermal stability, textural properties and acid site density were analyzed.

\section{Materials and Methods}

D-Xylose powder (99\%, Sigma Aldrich) was used in the experiments without further purification. Formic acid (98\%), levulinic acid (99\%) and acetic acid (99\%) were purchased from Sigma Aldrich and used for the preparation of calibration standards for HPLC analysis. Millipore grade water was used for preparing the solutions. Cordierite was obtained from Corning (Germany) and Disperal from Sasol Germany GmbH (Hamburg, Germany). Amberlyst DT was purchased from Rohm and Haas (France). Nafion NR40 beads were purchased from lon Power GmbH (Germany). 


\subsection{Catalyst preparation}

Pieces of cordierite (1-4 mm) were used as support. Sulfated zirconia $\left(\mathrm{SZ}, \mathrm{ZrO}_{2}\left(\mathrm{SO}_{4}{ }^{2-}\right)\right)$ and $\mathrm{Al}_{2} \mathrm{O}_{3}$ were prepared by impregnation of $\mathrm{ZrOCl}_{2} \cdot 8 \mathrm{H}_{2} \mathrm{O}$ and boehmite suspensions as precursors over cordierite following the method of Ledesma et al [38]. The resulting samples were dried at $105^{\circ} \mathrm{C}$ and then calcined in air $\left(\mathrm{SZ}\right.$ at $500{ }^{\circ} \mathrm{C} ; \mathrm{Al}_{2} \mathrm{O}_{3}$ at 450 $\left.{ }^{\circ} \mathrm{C}\right)$ for $2-5 \mathrm{~h}$ to obtain the corresponding active oxides. Saez et al [37] found that cordierite presented no appreciable reactivity. The inclusion of cordierite in the catalyst preparation is to provide the catalyst over a physical support for practical application. Reaction tests were conducted over Nafion NR40 and Amberlyst DT for the sake of comparison. Nafion NR40 was purified by treatment with hot hydrogen peroxide (5\%) to remove organic impurities and soaked in $5 \mathrm{wt} \%$ hot hydrochloric acid to remove cations and exchange them by protons. It was dried overnight at $105^{\circ} \mathrm{C}$. Amberlyst DT was also dried overnight at $105^{\circ} \mathrm{C}$ prior experimental tests.

\subsection{Catalytic activity tests}

Single component solutions of $D$-xylose $\left(186 \mathrm{mmol} \mathrm{l}^{-1}\right)$ were freshly prepared before the experiments. This specific xylose concentration was found to be in the prehydrolysate liquor from birch wood [39]. The first set of experiments was performed in the absence of solid acid catalysts. The second set of experiments was performed using $50 \mathrm{mg}$ of $\mathrm{Al}_{2} \mathrm{O}_{3}$ on cordierite, $\mathrm{SZ}$ on cordierite, Amberlyst DT or Nafion NR40 as a catalyst. In a typical experiment, the glass reactor was loaded with $3 \mathrm{ml}$ of the xylose solution and heated using a borosilicate glass reactor $\left(V=10 \mathrm{~cm}^{3}\right)$ with magnetic stirring $\left(600 \mathrm{~min}^{-1}\right)$ and microwave-assisted heating (Monowave 300, Anton Paar $\mathrm{GmbH}, \mathrm{Graz}$, Austria). After the reaction, the reactor was rapidly cooled to room temperature by utilizing compressed air. The highest temperature and the longest reaction time studied at the present work were $210{ }^{\circ} \mathrm{C}$ and $180 \mathrm{~min}$, respectively. After reaction, the solutions were tested for FUR yield, selectivity and xylose conversion at the reaction temperatures of 170,190 and $210{ }^{\circ} \mathrm{C}$ with different reaction times in the range of 2 $180 \mathrm{~min}$. In a typical experiment with solid acid catalyst, the glass reactor was loaded with $3 \mathrm{ml}$ of an aqueous solution of $28 \mathrm{~g} \mathrm{l}^{-1}$ xylose and $50 \mathrm{mg}$ of the catalyst. The reactor was placed in the microwave, heated to the set reaction temperature with an irradiation power of $\leq 850 \mathrm{~W}$ for maximum 1.5 min and kept at the reaction temperature for the set time. After the reaction, the reactor was rapidly cooled to room temperature by utilizing 
compressed air. For the reusability experiments, SZ on cordierite was collected after each use. It was washed with deionized water several times at room temperature and dried at $105^{\circ} \mathrm{C}$ prior to reuse. All catalytic activity tests were performed in duplicate with a standard deviation below 10\% (except for Nafion NR40, which its standard deviation is up to $33 \%)$.

\subsection{Reaction mechanism}

The kinetic modeling of xylose dehydration and FUR formation was based on the obtained experimental results following three possible reaction mechanisms. These reaction mechanisms were screened in order to find the optimal kinetic model explaining the xylose dehydration and FUR formation. Even though the reaction mechanism of FUR formation has been under discussion, these reaction mechanisms consider a pathway of FUR formation via an intermediate or xylose itself, a reaction mechanism did not consider a pathway solely via an intermediate. Using the xylose conversion data only in the modeling resulted in multiple equally well-fitting models with different mechanistic assumptions. The tested reaction mechanism considering the intermediate formation from xylose is as follows:

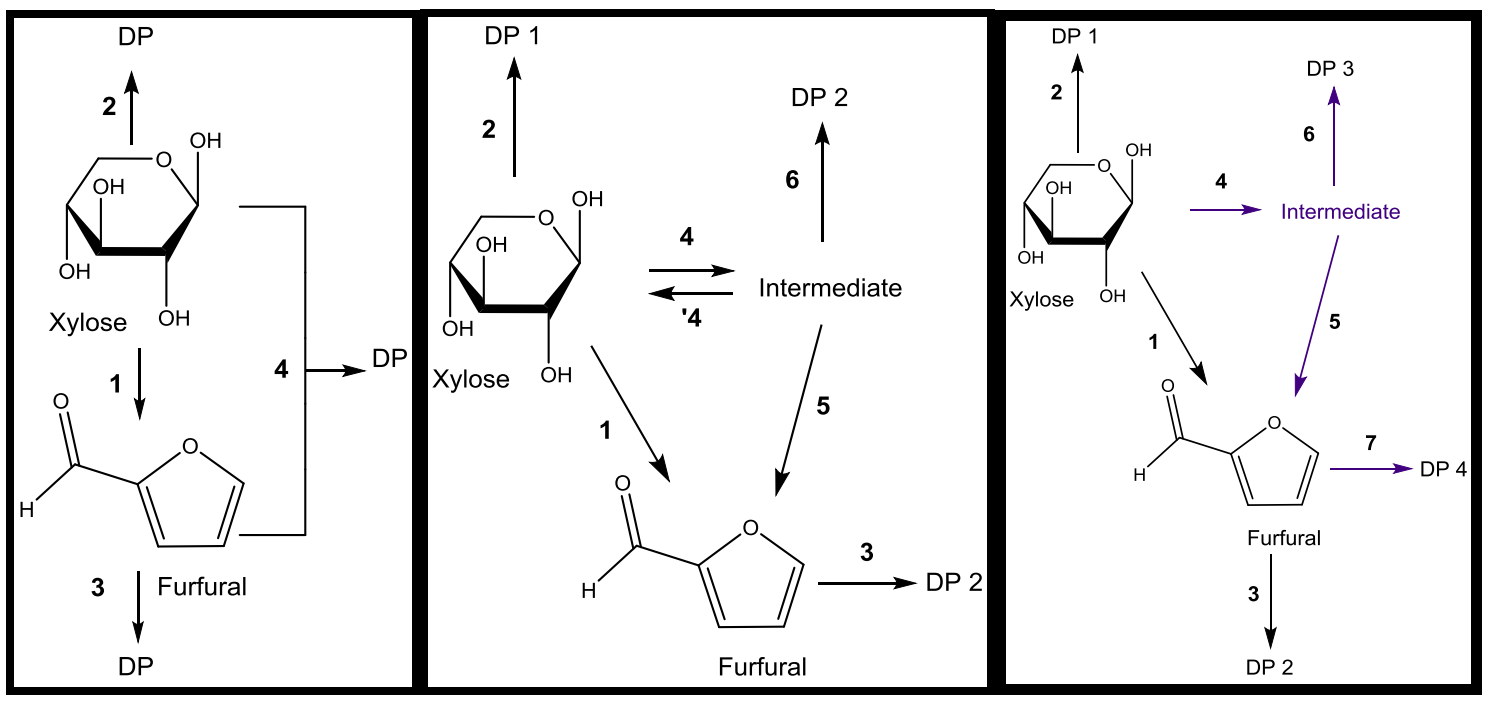

Scheme 1. FUR formation with Direct Xylose Decomposition
Scheme 2. FUR Formation with Side Reaction between Intermediate and FUR
Scheme 3. Parallel FUR Formation with Side Reaction Decomposition 
In the reaction model presented in scheme 1 , xylose can be converted to FUR directly $\left(k_{1}\right)$. In scheme 2 , FUR can be formed from xylose either stepwise with an intermediate product $\left(k_{4}+k_{5}\right)$, or via a direct or pseudo-direct reaction pathway $\left(k_{1}\right)$. In the reaction model presented in scheme 3, FUR is formed stepwise via an intermediate $\left(k_{4}+k_{5}\right)$ [39] or via a direct or pseudo-direct reaction pathway $\left(k_{1}\right)$. The latter scheme proposes a parallel reaction model from the intermediate. The produced FUR further forms degradation products (DP). Simultaneously, some fraction of xylose and intermediates (isomers or epimers of xylose) form degradation products also. The HPLC analysis did not identify any significant amount from products originating from side reactions between xylose and FUR, as well as the isomerization of the intermediate back to xylose. Previous kinetic studies have used either scheme 1 [40] or $2[39,41,42]$ using homogeneous catalysts. Different formation pathways include isomerization of xylose to other pentoses such as lyxose and xylulose. Dias et al [29] proposed a similar reaction mechanism for sulfated zirconia as scheme 2 shown in the present study, however there was no kinetic studies reported on the pathway of FUR formation from the intermediate.

\section{Results and Discussion}

\subsection{Auto-catalyzed dehydration of xylose}

Kinetic studies for auto-catalyzed xylose dehydration were performed at various reaction times at temperatures of 170,190 and $210{ }^{\circ} \mathrm{C}$. Figure 1 shows the FUR yield, xylose conversion and selectivity to FUR under these reaction conditions. The experimental tests can be considered as auto-catalyzed, since water is self-ionized to $\mathrm{H}^{+}$ and $\mathrm{OH}^{-}$ions that act as acid or base catalysts at the given temperature [43] . Later on, the carboxylic acids (formic, levulinic and acetic acid) or intermediates formed during the reaction, may have a catalytic effect [32, 39, 44]. The influence of the reaction temperature on the FUR yield and xylose conversion has been observed previously in similar work $[36,45]$. As Figure 1a displays, the FUR yield increased with reaction temperature up to 4 times from 170 to $190^{\circ} \mathrm{C}$ after the first $60 \mathrm{~min}$. When the reaction temperature was further increased from 190 to $210^{\circ} \mathrm{C}$, a 2 -fold increase can be seen. It was observed that at the highest temperature investigated in the present study $\left(210^{\circ} \mathrm{C}\right)$ the FUR yield firstly increases and thereafter decreases, as the reaction time prolongs. The 
decrease of FUR yield in prolonged reaction time occurs due to decomposition and polymerization with humins production $[46,47]$. Under the present experimental conditions, the maximum FUR yield $(48-49 \%)$ was reached after the first $60 \mathrm{~min}$ at $210^{\circ} \mathrm{C}$, which corresponds to a xylose conversion of $94 \%$ (Figure $1 \mathrm{~b}$ ) and a FUR selectivity of $52 \%$ (Figure $1 c$ ).

At reaction temperatures of 170 and $190{ }^{\circ} \mathrm{C}$, no distinct FUR yield culmination point, with subsequent rapid decrease was perceived during the reaction time range investigated. However, a yield decrease similar to that observed at $210{ }^{\circ} \mathrm{C}$ could be possibly observed at lower reaction temperatures ( 170 and $190{ }^{\circ} \mathrm{C}$ ) during prolonged reaction times. Nevertheless, the maximum yield unmistakably shifts to a longer reaction time with a decline of the reaction temperature. Furthermore, the FUR yield (and thus also the selectivity) decreases with decreasing the reaction temperature, this is in agreement with literature [48] . It is worth noting that the maximum selectivity to FUR observed in the auto-catalyzed conversion of xylose was $56-58 \%$ in the present studied range of reaction temperatures. These results agree with previously published papers [36] .
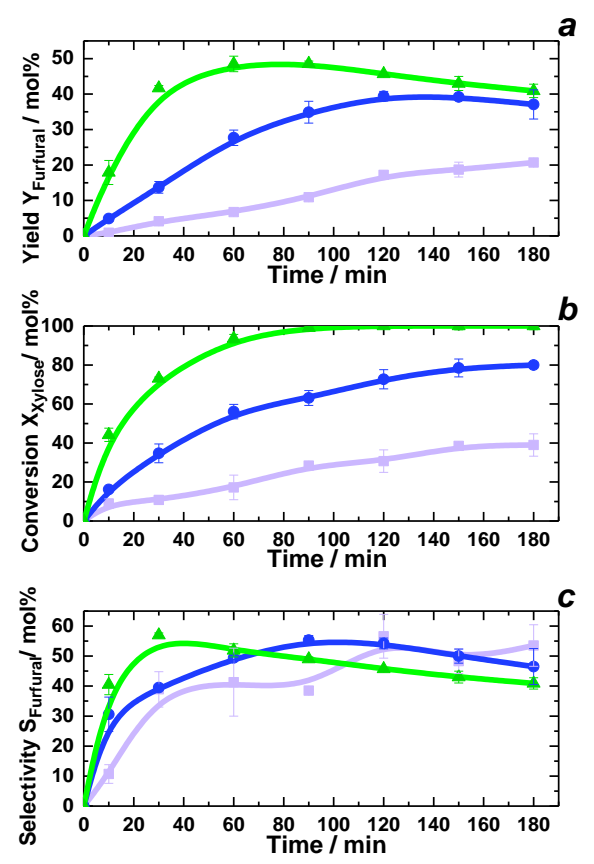

Figure 1. FUR yield (a), xylose conversion (b) and selectivity to FUR (c) at various reaction times during autocatalyzed conversion of xylose $186 \mathrm{mmol} \mathrm{I} \mathrm{I}^{-1}$ (purple square $-170^{\circ} \mathrm{C}$, blue circle $-190^{\circ} \mathrm{C}$, green triangle $-210{ }^{\circ} \mathrm{C}$, lines are to guide the eye). 


\subsection{Catalyzed dehydration of xylose by solid acids}

Figures $2 \mathrm{a}, 2 \mathrm{~b}$ and $2 \mathrm{c}$ show the FUR yield, xylose conversion and selectivity to FUR at various reaction times at 170,190 and $210{ }^{\circ} \mathrm{C}$ when $\mathrm{Al}_{2} \mathrm{O}_{3}$ is present in the dehydration of xylose. For SZ-catalyzed conversion of xylose Figures $2 \mathrm{~d}, 2 \mathrm{e}$ and $2 \mathrm{f}$ show the FUR yield, xylose conversion and selectivity to FUR, respectively. Similarly to the auto-catalyzed process, the FUR yield and the xylose conversion are visibly influenced by the reaction temperature. When using $\mathrm{Al}_{2} \mathrm{O}_{3}$, the maximum FUR yield is clearly influenced by the reaction temperature: at 170 ${ }^{\circ} \mathrm{C}$ starts from $26 \%$, it increases furthermore up to $43 \%$ at $210{ }^{\circ} \mathrm{C}$ (Figure 2a). This is similar to the effect observed when adding SZ, the maximum FUR yield increases from $36 \%$ to $41 \%$ when the reaction temperature is increased from $170{ }^{\circ} \mathrm{C}$ to $210^{\circ} \mathrm{C}$ (Figure 2d). After the maximum FUR yield has been reached, selectivity decreases because the FUR formed reacts further, via condensation and resinification [12]. Hence, humin formation was observed. These FUR yield losses were observed at reaction temperatures of 190 and $210^{\circ} \mathrm{C}$.

Similarly as in the auto-catalyzed process, conversion of xylose to FUR needs relatively high temperatures (Figure $2 \mathrm{~b}$ and $2 \mathrm{e}$ ). When using $\mathrm{Al}_{2} \mathrm{O}_{3}$ in the dehydration reaction of xylose, the maximum FUR yield (43\%, Figure $2 \mathrm{a}$ ) was reached in $30 \mathrm{~min}$ at $210^{\circ} \mathrm{C}$, corresponding to a xylose conversion of $91 \%$ (Figure $2 \mathrm{~b}$ ) and a FUR selectivity of $48 \%$ (Figure 2c). The maximum FUR yield (41\%) was reached after $2 \mathrm{~min}$ at $210^{\circ} \mathrm{C}$ during the SZ-catalyzed reaction, corresponding to a xylose conversion of $96 \%$ (Figure 2e) and a FUR selectivity of $43 \%$ (Figure $2 \mathrm{f}$ ). During the SZcatalyzed reaction, the maximum selectivity to FUR was $43 \%$ (at $210{ }^{\circ} \mathrm{C}$ in $2 \mathrm{~min}$ ) in contrast to $57 \%$ (at $210^{\circ} \mathrm{C}$ in $30 \mathrm{~min}$ ) obtained in the auto-catalyzed reaction system. When comparing the present results with the catalyzed system using $\mathrm{H}_{2} \mathrm{SO}_{4}[36]$ and a xylose concentration of $196 \mathrm{mmol} \mathrm{I}^{-1}$, the highest selectivity to FUR is $68 \%$ (at 180 ${ }^{\circ} \mathrm{C}$ in $5 \mathrm{~min}$ ) and $65 \%$ (at $200{ }^{\circ} \mathrm{C}$ in $1 \mathrm{~min}$, and at $220^{\circ} \mathrm{C}$ in $2 \mathrm{~min}$ ). 

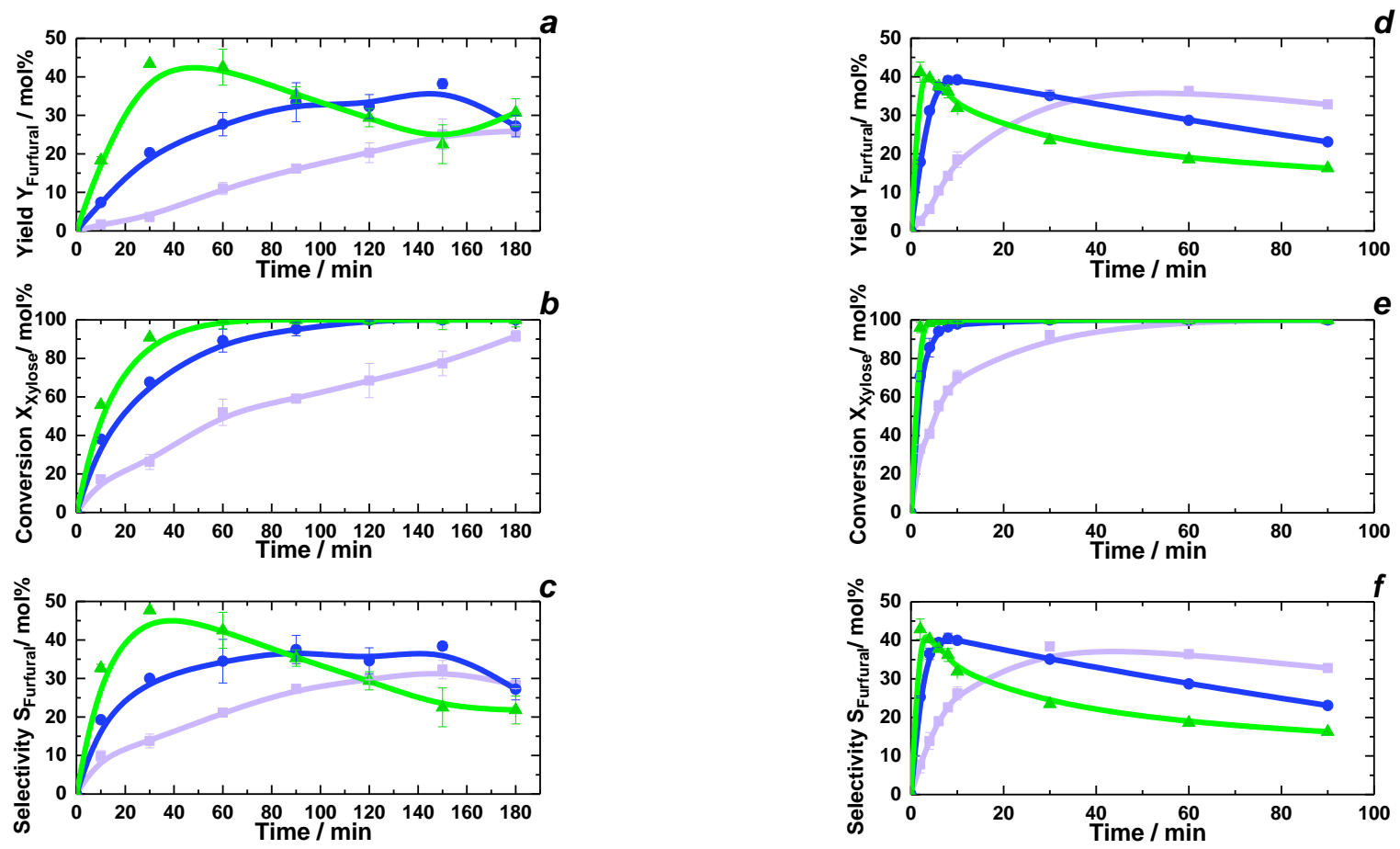

Figure 2. FUR yield $(a, d)$, xylose conversion $(b, e)$ and selectivity to $F U R(c, f)$ at various reaction times during conversion of xylose $186 \mathrm{mmol} \mathrm{I}^{-1}$ using $\mathrm{Al}_{2} \mathrm{O}_{3}$ on cordierite $(a, b, c)$ and SZ on cordierite $(d, e, f)$, respectively (purple square $-170^{\circ} \mathrm{C}$, blue circle $-190^{\circ} \mathrm{C}$, green triangle $-210^{\circ} \mathrm{C}$, lines are to guide the eye).

The FUR yield, xylose conversion and selectivity to FUR at various reaction times at $170{ }^{\circ} \mathrm{C}$ during conversion of xylose conducted with Amberlyst DT are shown in Figure A1. Amberlyst DT was only tested at $170{ }^{\circ} \mathrm{C}$ (maximum operational temperature) due to its limited hydrothermal stability as stated by the manufacturer. The maximum FUR yield (30\%) was reached in 60 min at $170{ }^{\circ} \mathrm{C}$ with a xylose conversion of $70 \%$.

The FUR yield, xylose conversion and selectivity to FUR at 170,190 and $210^{\circ} \mathrm{C}$ at various reaction times during xylose conversion conducted with Nafion NR40 are shown in Figure A2. In the same way that reaction temperature strongly influences FUR yield and xylose conversion in the auto-catalyzed process, the effect can be also observed when adding Nafion NR40. When adding Nafion NR40 pellets to the aqueous system, the maximum FUR yield is determined by the reaction temperature: at $170{ }^{\circ} \mathrm{C}$ starts from $33 \%$, furthermore it increases up to $41 \%$ at $210^{\circ} \mathrm{C}$. (Figure A2a). Due to the nature of the catalysts, the standard deviation increased at high reaction times and at high temperatures $\left(>190^{\circ} \mathrm{C}\right.$ ), even though the manufacturer guarantees its stability from 220 to 240 
${ }^{\circ} \mathrm{C}$ in aqueous systems. The catalysts clogged into each other making a barrier in the middle of the reactor. Therefore, the FUR and xylose concentration do not follow a smooth tendency. Nevertheless, xylose conversion behaves similarly to the auto-catalyzed system, since it requires longer reaction times to convert the same amount of xylose at a lower reaction temperature (Figure A2b). In the case of Nafion NR40, the maximum FUR yield (41\%, Figure $\mathrm{A} 2 \mathrm{a}$ ) was reached in $8 \mathrm{~min}$ at $210^{\circ} \mathrm{C}$, resulting on a xylose conversion of $70 \%$ (Figure $\mathrm{A} 2 \mathrm{~b}$ ) and a FUR selectivity of $60 \%$ (Figure A2c). During the Nafion NR40-catalyzed reaction, the maximum selectivity to FUR was $67 \%$ (at $210{ }^{\circ} \mathrm{C}$ in $2 \mathrm{~min}$ ) in contrast to $43 \%$ (at $210{ }^{\circ} \mathrm{C}$ in $2 \mathrm{~min}$ ) obtained in the SZ-catalyzed reaction system, and $52 \%$ (at $210{ }^{\circ} \mathrm{C}$ in $60 \mathrm{~min}$ ) in the auto-catalyzed reaction system.

The xylulose formation, a possible key intermediate $[35,49,50]$, was monitored by means of HPLC utilizing a pure xylulose solution as a reference. No detectable amounts of xylulose were observed in the initial xylose solutions. Under auto-catalyzed conditions at temperature reactions of $170-210^{\circ} \mathrm{C}$, xylulose formation was not detectable. This is in accordance with the low amount of xylulose yield $(<3$ mol\%) reported by Ershova et al [36] when employing a $196 \mathrm{mmol} \mathrm{I}^{-1}$ xylose solution at reactions temperatures of 180,200 and $220^{\circ} \mathrm{C}$.

Fig. A15a shows that the highest amount of xylulose (18 mol\%) was formed when employing alumina as catalyst in the dehydration of xylose at $170{ }^{\circ} \mathrm{C}$ in $120 \mathrm{~min}$. At this temperature, some amount of xylulose was still present even after $3 \mathrm{~h}$ of of treatment. When adding SZ (Fig. A15b), 46 mol\% was the highest amount of xylulose formed at $170{ }^{\circ} \mathrm{C}$ in $6 \mathrm{~min}$. When the reaction temperature increased to $190^{\circ} \mathrm{C}$, the amount of yielded xylulose decreased (27\%). At $210^{\circ} \mathrm{C}, 2 \%$ of xylulose was yielded in $2 \mathrm{~min}$. The extent of xylulose formation was highest at the lowest reaction temperature $\left(170^{\circ} \mathrm{C}\right)$ used in the present paper.

\subsection{Mathematical modeling}

Assuming a sequence of predominantly pseudo-first order reactions, the reactions of the model are assumed to follow the rate equations for similar elementary reactions. When the reactions are carried out in a batch reactor, the component mass balance for scheme 1 (assuming that the $k_{3}$ rate constant describes that the reaction consumes equal amount of moles of xylose and FUR) are: equations 7 and 8; 
$\frac{d[\text { Xylose }]}{d t}=-\left(k_{1}+k_{2}\right)[$ Xylose $]-\left(k_{4}\right)[$ Xylose $][$ FUR $]$

$\frac{d[F U R]}{d t}=k_{1}[$ Xylose $]-\left(\left(k_{3}\right)[F U R]+\left(k_{4}\right)[\right.$ Xylose $\left.][F U R]\right)$

for scheme 2 the component mass balance are shown in equations 9, 10 and 11;

$\frac{d[\text { Xylose }]}{d t}=-\left(k_{1}+k_{2}+k_{4}\right)[$ Xylose $]+k_{-4}[$ Intermediate $]$

$\frac{d[\text { Intermediate }]}{d t}=k_{4}[$ Xylose $]-\left(k_{-4}+k_{5}+k_{6}\right)[$ Intermediate $]$

$\frac{d[F U R]}{d t}=k_{5}[$ Intermediate $]+k_{1}[$ Xylose $]-k_{3}[F U R]$

For scheme 3 for the auto-catalyzed system equations 12 and 13 show the component mass balance:

$\frac{d[\text { Xylose }]}{d t}=-\left(k_{1}+k_{6}\right)[$ Xylose $]$

$\frac{d[F U R]}{d t}=k_{1}[$ Xylose $]-k_{3}[F U R]$

And for the solid acid-catalyzed system equations 14,15 and 16 :

$\frac{d[\text { Xylose }]}{d t}=-\left(k_{1}+k_{2}+k_{4}\right)[$ Xylose $]$

$\frac{d[\text { Intermediate }]}{d t}=k_{4}[$ Xylose $]-\left(k_{5}+k_{6}\right)[$ Intermediate $]$

$\frac{d[F U R]}{d t}=k_{1}[X y$ lose $]+k_{5}[$ Intermediate $]-\left(k_{3}+k_{7}\right)[F U R]$

where $k_{1}, k_{2}, k_{3}, k_{4}, k_{5}, k_{6}, k_{7}$ are rate constants and [Xylose], [Intermediate], [FUR] are concentrations (in mol I-1) for xylose, intermediate and FUR, respectively.

The fittings of the kinetic models of the experimental results with pure xylose solution and solid acid catalysts corresponding to scheme 3 are shown in figures 3-5. The fittings show that the chemical intermediate concentration is strongly influenced by the reaction temperature and the presence of the solid acid catalysts. As it 
can be seen in figures 4 and 5, the concentration of the intermediate decreases when the reaction temperature increases. In the case of the $\mathrm{Al}_{2} \mathrm{O}_{3}$ (Figure 5), the concentration of the chemical intermediate reaches up to 32 $\mathrm{mmol} \mathrm{I}^{-1}$ at $170^{\circ} \mathrm{C}$. When adding $\mathrm{SZ}$, this concentration increases up to $86 \mathrm{mmol} \mathrm{I}^{-1}$ (Figure 4) also at $170^{\circ} \mathrm{C}$.

It has been reported previously that $\mathrm{SZ}$ possesses $\mathrm{Br} \varnothing$ nsted acid (BA) sites, while $\mathrm{Al}_{2} \mathrm{O}_{3}$ presents a combination of BA and Lewis acid (LA) sites. BA are linked to direct pentose dehydration into FUR, and LA tend to isomerize pentoses into chemical intermediates, such as xylulose $[12,20,35,51-53]$. However, the discussion on the coexistence of BA and LA sites on the surface of SZ and how to properly measure it still continues [54-56]. Furthermore, the discussion on the relationship between LA and BA sites effect on the dehydration mechanism is largely unclear [57]. The extent of sulfation on the SZ was low (Table 5), which might favor the presence of LA [54], thus promoting reaction pathways with chemical intermediates, such as xylulose. For both systems employing solid acid catalysts ( $\mathrm{SZ}$ and $\mathrm{Al}_{2} \mathrm{O}_{3}$ ), the highest concentration of xylulose is reached at the lowest temperature $\left(170^{\circ} \mathrm{C}\right)$. This is in agreement with previous studies $[35,36]$, which highlighted that the reaction of xylulose to FUR is favored at low temperatures in the presence of LA over the reaction of xylose to FUR. In contrast, at high temperatures LA catalysts lose the pathway via xylulose, due to gradual transformation of LA into BA, which can be seen in Figure 4 and 5 where xylulose disappears as temperature increases. Their presence also involves the formation of degradation products such as carboxylic acids (formic, acetic and levulinic acid). These compounds were identified but not quantified. The figures corresponding to the models following scheme 1 and scheme 2 are displayed on Figures A3-A10.
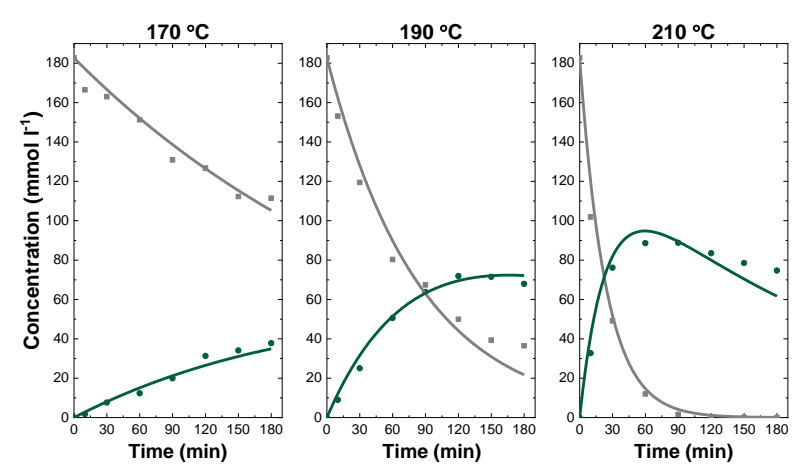
Figure 3. Scheme 3 and concentrations of FUR (green) and xylose (gray) at temperatures of 170,190 and $210{ }^{\circ} \mathrm{C}$ in auto-catalyzed system. (Experimental-circle, modeled-solid lines).
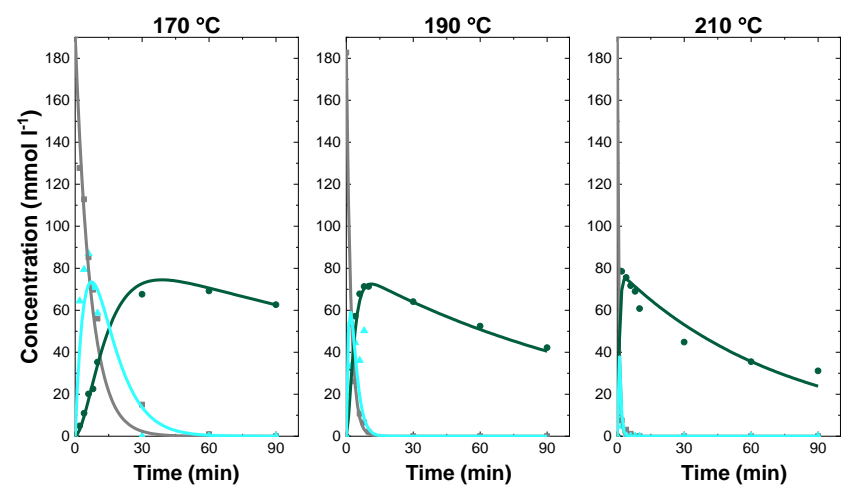

Figure 4. Scheme 3 and concentrations of FUR (green), xylose (grey) and xylulose (blue) at temperatures of 170, 190 and $210^{\circ} \mathrm{C}$ with SZ. (Experimental-circle, modeled-solid lines).
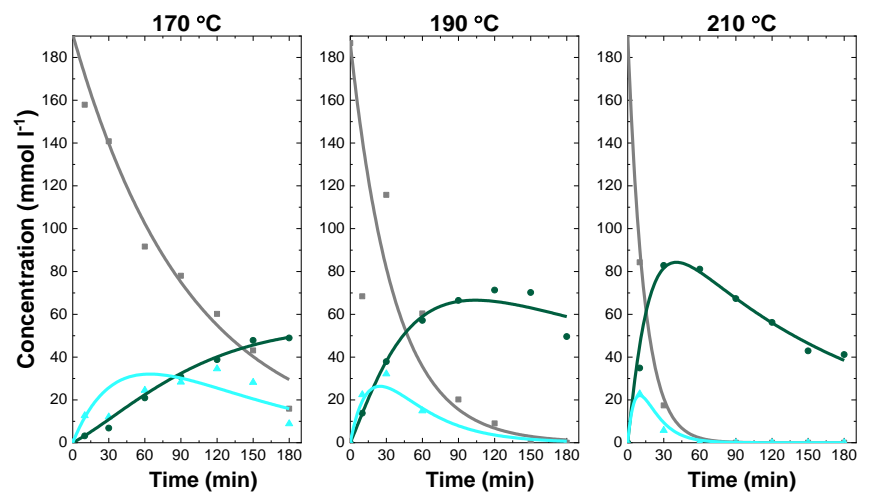

Figure 5. Scheme 3 and concentrations of FUR (green), xylose (grey) and xylulose (blue) at temperatures of 170, 190 and $210^{\circ} \mathrm{C}$ with $\mathrm{Al}_{2} \mathrm{O}_{3}$. (Experimental-circle, modeled-solid lines).

\subsection{Model fitting}

The Figures 3-5 show that Scheme 3 predicts xylose and FUR concentrations properly. The models fit all the xylose conversion experimental data as well as FUR formation. The main difference between the three models is that scheme 3 includes a parallel reaction when the solid acid catalyst is added, thus describing the formation of an intermediate (xylulose). The best fitting of the model to experimental data was obtained considering a parallel pathway via an intermediate compound leading to the formation of FUR when using solid acid catalysts (Scheme 3) and a direct formation of FUR from xylose in the auto-catalyzed system. 
In order to be able to elucidate relative contributions of individual steps (Table 1), the pre-exponential factors and the activation energies were evaluated by fitting the models to the data. The rate constants were then calculated from the pre-exponential factor and the activation energy according to the Arrhenius equation. When SZ and $\mathrm{Al}_{2} \mathrm{O}_{3}$ are added the temperature dependence of $k_{i}$ is more pronounced, indicating that the reaction rates in the presence of solid acid catalyst are subtler to the reaction temperature. Tables 1-3 display the obtained kinetic parameters and the activation energies for each reaction step.

As Table 1 reveals, the rate constants for the xylose dehydration into FUR $\left(k_{1}\right)$ increase as the temperature increases in the auto-catalyzed system. Similar to this, the rate constants for the decomposition of xylose $\left(k_{2}\right)$ and FUR $\left(k_{3}\right)$ also increase as the reaction temperature increases. The addition of $\mathrm{SZ}$ and $\mathrm{Al}_{2} \mathrm{O}_{3}$ as solid acid catalysts adds a reaction for the xylose isomerization $\left(k_{4}\right)$, its dehydration to FUR $\left(k_{5}\right)$ and the further decomposition products from the chemical intermediate $\left(k_{6}\right)$ and from FUR $\left(k_{7}\right)$. This observation is supported by the fact that sugar isomerization reactions are catalyzed by the presence of LA sites $[35,36,51,57,58]$. The addition of SZ and $\mathrm{Al}_{2} \mathrm{O}_{3}$, increases the xylose decomposition $\left(k_{2}\right)$. These results are in agreement with You et al [59], which confirms that LA sites are involved in the formation of humin from xylose dehydration. The rate constant for the decomposition of FUR $\left(k_{3}, k_{7}\right)$ in the auto-catalyzed and catalyzed systems with $\mathrm{SZ}$ and $\mathrm{Al}_{2} \mathrm{O}_{3}$ are negligible. At the studied conditions when $\mathrm{SZ}$ and $\mathrm{Al}_{2} \mathrm{O}_{3}$ are added to the system, the formation of decomposition products is found to decrease in the order $k_{6}>k_{2}>k_{7}>k_{3}$. This could be due to the introduction of BA sites, which increase the decomposition rate of pentoses [37].

Table 1. Kinetic rate constants $\mathrm{k}_{\mathrm{i}}\left(\mathrm{min}^{-1}\right)$ at each experimental temperature for auto-catalyzed and acid-catalyzed systems following Scheme 3.

\begin{tabular}{lllllllll}
\hline $\mathrm{T},\left({ }^{\circ} \mathrm{C}\right)$ & Solid acid & $\mathrm{k}_{1}$ & $\mathrm{k}_{2}$ & $\mathrm{k}_{3}$ & $\mathrm{k}_{4}$ & $\mathrm{k}_{5}$ & $\mathrm{k}_{6}$ & $\mathrm{k}_{7}$ \\
\hline 170 & - & & & & & & & \\
& & 0.002 & 0.002 & 0.001 & & & & \\
190 & - & 0.007 & 0.005 & 0.002 & & & &
\end{tabular}




$\begin{array}{llllllllll}210 & - & 0.028 & 0.014 & 0.004 & & & & \\ 170 & \mathrm{SZ} & 0.002 & 0.002 & 0.001 & 0.13 & 0.065 & 0.093 & 0.002 \\ 190 & \mathrm{SZ} & 0.007 & 0.005 & 0.002 & 0.54 & 0.43 & 0.64 & 0.004 \\ 210 & \mathrm{SZ} & 0.028 & 0.014 & 0.004 & 2.02 & 2.41 & 3.71 & 0.008 \\ 170 & \mathrm{Al}_{2} \mathrm{O}_{3} & & & & & & & \\ 190 & \mathrm{Al}_{2} \mathrm{O}_{3} & 0.002 & 0.002 & 0.001 & 0.008 & 0.006 & 0.003 & 0.002 \\ & & & & & & & & \\ 210 & \mathrm{Al}_{2} \mathrm{O}_{3} & 0.007 & 0.005 & 0.002 & 0.016 & 0.015 & 0.011 & 0.002 \\ & & & & & & & & \\ \end{array}$

This is in line with the activation energies presented in Table 3. The ratio of the reaction rate $k_{1} / k_{2}$ indicates that the dehydration of xylose is faster than the formation of decomposition products (Table 2). At the same time, the high ratio of $k_{1} / k_{3}$ shows that the reaction to FUR from xylose is much faster than the decomposition of FUR. When adding SZ, the low ratio values of $k_{5} / k_{6}$ indicate that the intermediate decomposes faster than FUR is formed from it. This could be due to the introduction of LA sites, which are known to promote humin formation and decomposition into $\mathrm{C}_{1}-\mathrm{C}_{3}$ products $[35,59]$. Nevertheless, in the case of $\mathrm{Al}_{2} \mathrm{O}_{3}$, the opposite is true except at high temperatures $\left(210^{\circ} \mathrm{C}\right)$. This could be explained by the presence of LA sites that at high temperatures are transformed into BA sites $[10,55]$. Furthermore, the ratio $k_{1} / k_{4}$ desmonstrates that the addition of solid acid catalysts, which present LA sites isomerize xylose into other pentoses (xylulose) as other authors have previously reported $[12,20,35,53,58,60]$. Furthermore, when $S Z$ is added to the reaction the ratio $k_{3} / k_{7}$ decreases as temperature increases. However, in the case of $\mathrm{Al}_{2} \mathrm{O}_{3}$, the rate of decomposition products forming from FUR in the auto-catalyzed system is faster than in the solid acid-catalyzed system. Nevertheless, $k_{3}$ and $k_{7}$ values are negligible as Table 1 shows. 
Table 2. Ratio of selected kinetic rate constants at each experimental temperature for auto-catalyzed and soli acid-catalyzed systems following Scheme 3.

\begin{tabular}{|c|c|c|c|c|c|c|}
\hline $\mathrm{T},\left({ }^{\circ} \mathrm{C}\right)$ & Solid acid & $\mathrm{k}_{1} / \mathrm{k}_{2}$ & $\mathrm{k}_{1} / \mathrm{k}_{3}$ & $\mathrm{k}_{5} / \mathrm{k}_{6}$ & $\mathrm{k}_{1} / \mathrm{k}_{4}$ & $k_{3} / k_{7}$ \\
\hline 170 & - & 1.07 & 1.23 & & & \\
\hline 190 & - & 1.51 & 2.84 & & & \\
\hline 210 & - & 2.11 & 6.33 & & & \\
\hline 170 & $S Z$ & 1.07 & 1.23 & 0.70 & 0.01 & 0.81 \\
\hline 190 & SZ & 1.51 & 2.84 & 0.67 & 0.01 & 0.66 \\
\hline 210 & SZ & 2.11 & 6.33 & 0.65 & 0.01 & 0.54 \\
\hline 170 & $\mathrm{Al}_{2} \mathrm{O}_{3}$ & 1.07 & 1.23 & 1.77 & 0.21 & 0.62 \\
\hline 190 & $\mathrm{Al}_{2} \mathrm{O}_{3}$ & 1.51 & 2.84 & 1.36 & 0.44 & 1.09 \\
\hline 210 & $\mathrm{Al}_{2} \mathrm{O}_{3}$ & 2.11 & 6.33 & 0.97 & 0.92 & 1.73 \\
\hline
\end{tabular}

The frequency factors and activation energies for each reaction step are shown in Table 3 . For comparison reasons, some published data related to similar reaction steps are also shown in Table A4. To the authors' knowledge, the frequency factors and activation energies of xylose isomerization to the intermediate, to FUR and degradation products formation from the intermediate following scheme 3 have not been previously reported in literature for neither auto-catalyzed nor catalyzed reactions with solid acid catalysts present. In comparison to the auto-catalyzed system, when using $\mathrm{SZ}$ and $\mathrm{Al}_{2} \mathrm{O}_{3}$ in the system the activation energies increased. The activation energies calculated when employing $\mathrm{SZ}$ and $\mathrm{Al}_{2} \mathrm{O}_{3}$ in the present study are higher than those published before the present study. These divergences between data could be possibly explained by either implementation of 
simplified reaction mechanism $[2,51,61-64]$ or utilization of subcritical and supercritical reaction condition in earlier studies [65].

Table 3. Frequency factors $\left(A_{r e f, i} \min ^{-1}\right)$ and activation energies $\left(E_{a i}, \mathrm{~kJ} \mathrm{~mol}^{-1}\right)$ for the kinetic model proposed in scheme 3; auto-catalyzed system, $\mathrm{SZ}$ - and $\mathrm{Al}_{2} \mathrm{O}_{3}$-catalyzed system.

\begin{tabular}{|c|c|c|c|c|c|c|c|}
\hline \multirow{2}{*}{\multicolumn{2}{|c|}{$\begin{array}{l}\text { Scheme } \\
\text { Number }\end{array}$}} & \multirow{2}{*}{$\begin{array}{l}A_{\text {ref }, \text { (auto- }} \\
\text { catalyzed) }\end{array}$} & \multirow{2}{*}{$\begin{array}{l}\mathrm{E}_{\mathrm{ai}} \text { (auto- } \\
\text { catalyzed) }\end{array}$} & \multirow{2}{*}{$\overline{A_{\text {ref }, i}(S Z)}$} & \multirow{3}{*}{$\overline{\mathrm{E}_{\mathrm{ai}}(\mathrm{SZ})}$} & \multirow{3}{*}{$\mathrm{A}_{\mathrm{ref}, \mathrm{i}}\left(\mathrm{Al}_{2} \mathrm{O}_{3}\right)$} & \multirow{3}{*}{$\mathrm{E}_{\mathrm{ai}}\left(\mathrm{Al}_{2} \mathrm{O}_{3}\right)$} \\
\hline & & & & & & & \\
\hline Scheme & (1) & $3.2 \times 10^{+11}$ & 121 & & & & \\
\hline \multirow[t]{6}{*}{3} & (2) & $1.9 \times 10^{+9}$ & 103 & & & & \\
\hline & (3) & 2900 & 53.7 & & & & \\
\hline & (4) & & & $3.42 \times 10^{+13}$ & 122 & $1.92 \times 10^{+5}$ & 63 \\
\hline & (5) & & & $5.85 \times 10^{+17}$ & 161 & $3.8 \times 10^{+7}$ & 83 \\
\hline & (6) & & & $1.99 \times 10^{+18}$ & 164 & $3.54 \times 10^{+10}$ & 111 \\
\hline & (7) & & & $7.02 \times 10^{+5}$ & 73 & 0.031 & 10 \\
\hline
\end{tabular}

Reaction rate constants, frequency factors and activation energies when using Nafion NR40 can be seen in Tables $A 1, A 2$ and A3. Frequency factors and activation energies for the kinetic models (scheme 1 and 2); in the autocatalyzed system and when using $\mathrm{SZ}$ and $\mathrm{Al}_{2} \mathrm{O}_{3}$ can be seen in Table $\mathrm{A} 4$.

\subsection{Catalyst characterization}

Solid acid catalysts before and after hydrothermal reaction were characterized based on the highest FUR yield reached at the three selected temperatures $\left(170,190\right.$ and $\left.210{ }^{\circ} \mathrm{C}\right)$. The notation for $\mathrm{SZ}$ after hydrothermal 
reaction at $170{ }^{\circ} \mathrm{C}$ is $\mathrm{SZ}_{170}$ (where the highest FUR yield was reached). However, for $\mathrm{Al}_{2} \mathrm{O}_{3}$ a hyphen will be added when reaction temperature is followed, e.g. $\mathrm{Al}_{2} \mathrm{O}_{3-210}$.

\subsubsection{Morphology of the solid acid catalysts}

Fig. 6 shows, as an example, the scanning electron micrographs of $\mathrm{Al}_{2} \mathrm{O}_{3 \text { fresh }}$ and $\mathrm{Al}_{2} \mathrm{O}_{3-210}$ catalyst samples. On the $\mathrm{Al}_{2} \mathrm{O}_{3 \text { fresh }}$ sample, Fig. 6(a), the alumina plates can be seen on the surface. Fig. 6(c) corresponds to $\mathrm{Al}_{2} \mathrm{O}_{3}-210$ on cordierite sample $\left(210{ }^{\circ} \mathrm{C}\right.$ after $\left.30 \mathrm{~min}\right)$. Fig. $6(\mathrm{~b}, \mathrm{~d})$ correspond to $\mathrm{Al}_{2} \mathrm{O}_{3 \text { fresh }}$ and $\mathrm{Al}_{2} \mathrm{O}_{3-210}$ on cordierite sample at a higher magnification. It can be seen on Fig. $6(c, d)$ humin formation on the surface of the metal oxide catalyst samples (see spheres marked with arrows).
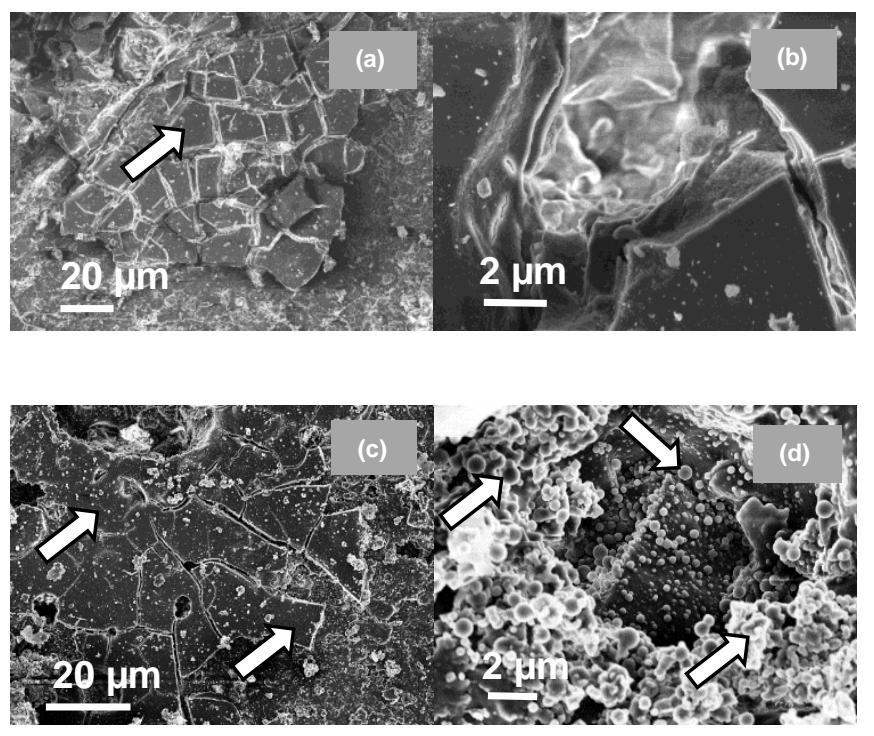

Figure 6. SEM images of $(a, b) \mathrm{Al}_{2} \mathrm{O}_{3}$ on cordierite, (c,d) $\mathrm{Al}_{2} \mathrm{O}_{3^{-2} 210}$ on cordierite.

SZ on cordierite can be seen on Fig. 7(a,b), the SEM images show similitude of the SZ characteristically cylindricallike structure as reported by Al-Hazmi and Apblett [66]. $\mathrm{SZ}_{210}$ on cordierite catalyst sample is shown on Fig. 7(c,d) after the hydrothermal reaction at $210{ }^{\circ} \mathrm{C}$ for $2 \mathrm{~min}$. On the surface of the spent samples appeared spheres (marked by arrows in Fig. $7(c, d)$ ), which are humins formed in the hydrothermal reaction. 

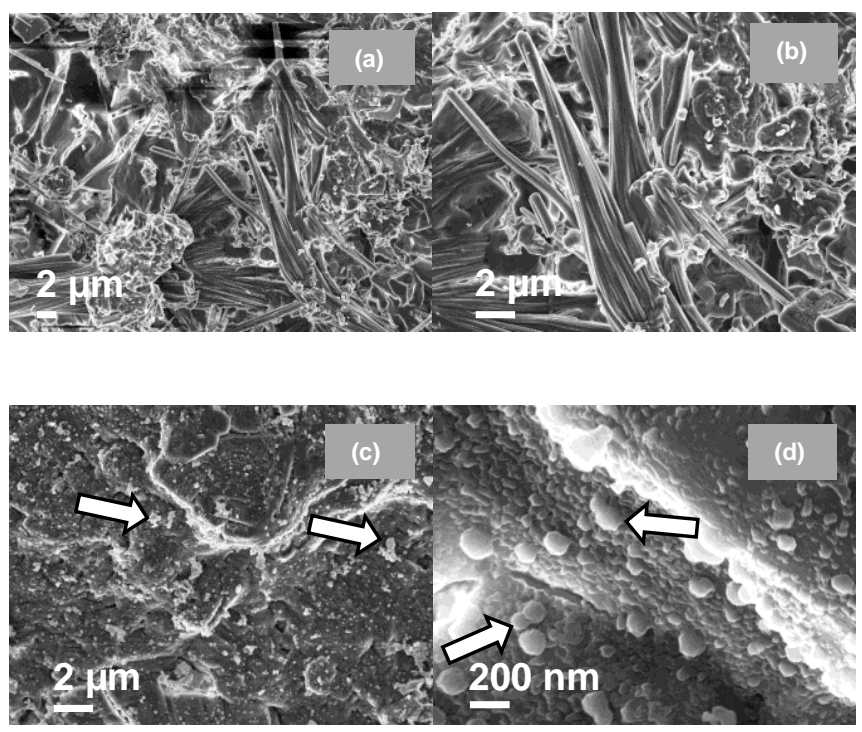

Figure 7. SEM images of $(a, b) S Z$ on cordierite, $(c, d) S Z_{210}$ on cordierite.

SEM images of Nafion $\mathrm{NR40}_{\text {fresh }}$ and Nafion $\mathrm{NR40}_{210}$, Amberlyst $\mathrm{DT}_{\text {fresh }}$ and Amberlyst $\mathrm{DT}_{170}$, as well as $\mathrm{SZ}_{170}, \mathrm{SZ}_{190}$ and $\mathrm{SZ}_{\text {reused }}$ can be seen in Figures A11, A12 and A13, respectively. The structure of these spherical humin particles 2-3 $\mu \mathrm{m}$ in size agree with the findings of Van Zandvoort et al[46] , who also studied humin formation from acidcatalyzed dehydration of xylose under standard reaction conditions of $180{ }^{\circ} \mathrm{C}, 1 \mathrm{M}$ solution of sugar and $0.01 \mathrm{M}$ $\mathrm{H}_{2} \mathrm{SO}_{4}$. The formation of carbonaceous deposits is detrimental to the reaction as can be seen in Figures 1 and 2.

\subsection{2. $\mathrm{N}_{2}$-sorption}

The BET (Brunauer-Emmett-Teller) specific surface areas and pore volumes obtained by the nitrogen physisorption are compiled in Table 4. Both polymeric resins (Amberlyst DT and Nafion NR40) show low BET specific surface area $\left(0.2 \mathrm{~m}^{2} \mathrm{~g}^{-1}\right)$, but $\mathrm{Al}_{2} \mathrm{O}_{3}$ sample exhibits a higher surface area $\left(11.8 \mathrm{~m}^{2} \mathrm{~g}^{-1}\right)$. SZ sample also shows a low BET of $0.8 \mathrm{~m}^{2} \mathrm{~g}^{-1}$ (as reported by Casanovas et al [67] the $A_{B E T}$ of the support (cordierite) is $0.1 \mathrm{~m}^{2} \mathrm{~g}^{-1}$ ). The pore width distributions shown in Figure S14 reveal a narrow pore width of approximately $45 \AA$ in $\mathrm{Al}_{2} \mathrm{O}_{3}$ on cordierite. These pores occupy a large part of the total pore volume in $\mathrm{Al}_{2} \mathrm{O}_{3}$ on cordierite. There are three other broader pore widths at 115, 153 and $311 \AA$ with high pore volumes. There can be seen two similar pore width distributions in SZ at 193 and $310 \AA$ with high pore volumes. The pore volume for both commercial polymeric 
resins is below $4 \times 10^{-5} \mathrm{~cm}^{3} \mathrm{~g}^{-1}$. The pore width distributions of Amberlyst DT reveal a broad pore width of approximately $604 \AA$ A. Nafion NR40 shows a small pore width at $513 \AA$.

Table 4. Textural properties of solid acid catalysts (i.e., $A_{B E T}, V_{p}$ and $\left.d_{p}\right)$.

\begin{tabular}{llll}
\hline catalyst & $\mathrm{A}_{\mathrm{BET}} / \mathrm{m}^{2} \mathrm{~g}^{-1}$ & $\mathrm{~V}_{\mathrm{p}} / \mathrm{cm}^{3} \mathrm{~g}^{-1}$ & $\mathrm{~d}_{\mathrm{p}} / \mathrm{nm}$ \\
\hline $\mathrm{Al}_{2} \mathrm{O}_{3}$ & 11.8 & $10^{-2}$ & 4.4 \\
$\mathrm{ZrO}_{2}\left(\mathrm{SO}_{4}{ }^{2-}\right)$ & 0.8 & $10^{-3}$ & 5.0 \\
Nafion NR40 & 0.2 & $4 \times 10^{-5}$ & 1.4 \\
Amberlyst DT & 0.2 & $10^{-4}$ & 1.1 \\
& & & \\
\hline
\end{tabular}

As reported by other researchers $[57,68]$, a large surface area is preferable to ease accessibility of xylose (for adsorption and further dehydration purposes). The effect of a higher $A_{B E T}$, hence a higher amount of active sites available in the reaction to dehydrate xylose, in the case of $\mathrm{Al}_{2} \mathrm{O}_{3}$ could be observed in Figure 2 with a higher selectivity (48\%) in comparison to SZ (43\%). The pore widths of solid acid catalysts used in the present study are larger than optimal pore widths reported previously to provide accessibility for xylose and FUR molecules [69].

\subsection{Catalyst stability}

\subsection{1. $\mathrm{NH}_{3}$-TPD}

To obtain insight into the catalytic activity tendency, Table 5 shows the total density of acid sites determined by $\mathrm{NH}_{3}$-TPD. Even though there are continuing discussions about the acidity of $\mathrm{SZ}[70,71]$ and $\mathrm{Al}_{2} \mathrm{O}_{3}$, clearly, the acidity of alumina (137.2 $\mu \mathrm{mol}$ of $\mathrm{NH}_{3} \mathrm{~g}^{-1}$ ) on cordierite was much higher than that of $\mathrm{SZ}\left(38.4 \mu \mathrm{mol}\right.$ of $\left.\mathrm{NH}_{3} \mathrm{~g}^{-1}\right)$. This comparison agrees with that reported by Saez et al [37], which confirms that $\mathrm{Al}_{2} \mathrm{O}_{3}$ have higher total acid 
sites than $\mathrm{SZ}$. This is in contrast with the acid site density of $\mathrm{SZ}$ and $\mathrm{Al}_{2} \mathrm{O}_{3}$ reported by other researchers $[2,12,72]$, the reported values could be due to the synthesis method employed.

After hydrothermal reaction at $210^{\circ} \mathrm{C}$ in $30 \mathrm{~min}$, the alumina lost more than half of its total acid sites $(41.9 \mu \mathrm{mol}$ of $\left.\mathrm{NH}_{3} \mathrm{~g}^{-1}\right)$, as well as $\mathrm{SZ}$ after hydrothermal reaction at $190{ }^{\circ} \mathrm{C}$ in $10 \mathrm{~min}\left(27.8 \mu \mathrm{mol}\right.$ of $\left.\mathrm{NH}_{3} \mathrm{~g}^{-1}\right)$. It is assumed that the loss of acid sites under experimental conditions is due to high pressure ( $>12$ bar) and hydrothermal conditions in the reactor.

Table 5. Total acid site density of calcined

catalysts determined by TPD of $\mathrm{NH}_{3}$ from 100

${ }^{\circ} \mathrm{C}$ to $600{ }^{\circ} \mathrm{C}$.

\begin{tabular}{ll}
\hline catalyst & total acid sites ( $\mu \mathrm{mol}$ of \\
& $\left.\mathrm{NH}_{3} \mathrm{~g}^{-1}\right)$ \\
\hline $\mathrm{Al}_{2} \mathrm{O}_{3}$ & 137.2 \\
$\mathrm{Al}_{2} \mathrm{O}_{3-210}$ & 41.9 \\
$\mathrm{SZ}$ & 38.4 \\
$\mathrm{SZ}$ & \\
& 27.8 \\
\hline
\end{tabular}

The ion exchange capacities of the polymeric resins were verified by back-titration following the method reported by Goertzen et al [73]. Table A5 shows that Amberlyst DT (a macroreticular, sulfonic acid polymeric catalyst) has three times more acid sites $\left(3.1 \mathrm{meq}^{-1}\right)$ than Nafion NR40 in bead form $\left(1.0 \mathrm{meq}^{-1}\right)$. According to the manufacturer, Nafion NR40 in bead-form has an ion exchange capacity of 1.0 meq $\mathrm{g}^{-1}$. Amberlyst DT (a macroreticular, sulfonic acid polymeric catalyst) has a concentration of acid sites of $\geq 3.1$ meq $^{-1}$. 


\subsubsection{XPS}

Apart from the thorough microstructural analysis of the above samples, a detailed XPS analysis was performed to get a deeper insight about the surface composition of the materials. In Table 6 the binding energy values and surface atomic composition of metal oxides before and after hydrothermal reaction are shown.

Table 6. XPS data of $\mathrm{SZ}$ and $\mathrm{Al}_{2} \mathrm{O}_{3}$ on cordierite before and after the hydrothermal reaction at different temperatures.

\begin{tabular}{|c|c|c|c|c|}
\hline \multirow[t]{2}{*}{ Sample } & \multirow[t]{2}{*}{ Name } & Binding & \multirow[t]{2}{*}{ Element } & \multirow{2}{*}{$\begin{array}{l}\% \text { At } \\
\text { Conc }\end{array}$} \\
\hline & & $\begin{array}{l}\text { Energy } \\
(\mathrm{eV})\end{array}$ & & \\
\hline \multirow[t]{4}{*}{$\overline{S Z_{\text {fresh }}}$} & $01 \mathrm{~s}$ & 531.9 & 0 & 52.9 \\
\hline & C 1s & 279.7 & $C$ & 29.4 \\
\hline & $S 2 p$ & 168.5 & $S$ & 15.1 \\
\hline & $\operatorname{Zr} 3 d$ & 182.4 & $\mathrm{Zr}$ & 2.7 \\
\hline \multirow[t]{4}{*}{$S Z_{170}$} & $01 \mathrm{~s}$ & 531.7 & 0 & 23.6 \\
\hline & C 1s & 284.2 & C & 75.8 \\
\hline & $S 2 p$ & 169.0 & $S$ & 0.1 \\
\hline & $\operatorname{Zr} 3 d$ & 182.3 & $\mathrm{Zr}$ & 0.5 \\
\hline \multirow[t]{2}{*}{$\mathrm{SZ}_{190}$} & $01 \mathrm{~s}$ & 531.8 & 0 & 30.4 \\
\hline & C 1s & 284.3 & C & 67.1 \\
\hline
\end{tabular}




\begin{tabular}{|c|c|c|c|c|}
\hline & $S 2 p$ & 168.3 & $S$ & 0.7 \\
\hline & $\mathrm{Zr} \mathrm{3d}$ & 182.3 & $\mathrm{Zr}$ & 1.8 \\
\hline \multirow[t]{4}{*}{$\mathrm{SZ}_{210}$} & 0 1s & 531.7 & 0 & 36.2 \\
\hline & $\mathrm{C} 1 \mathrm{~s}$ & 283.8 & C & 60.6 \\
\hline & $S 2 p$ & 168.2 & $S$ & 0.7 \\
\hline & $\mathrm{Zr} 3 \mathrm{~d}$ & 182.4 & $\mathrm{Zr}$ & 2.5 \\
\hline \multirow[t]{3}{*}{$S Z_{\text {reused }}$} & 0 1s & 532.2 & 0 & 48.8 \\
\hline & C 1s & 284.2 & $C$ & 48.9 \\
\hline & Zr 3d & 182.4 & $\mathrm{Zr}$ & 2.3 \\
\hline \multirow[t]{4}{*}{$\mathrm{Al}_{2} \mathrm{O}_{3 \text { fresh }}$} & 0 1s & 528.3 & $\mathrm{O}$ & 43.8 \\
\hline & C 1s & 281.7 & $\mathrm{C}$ & 23.6 \\
\hline & $\mathrm{Al} 2 \mathrm{~s}$ & 118.7 & $\mathrm{Al}$ & 19.5 \\
\hline & $\operatorname{Mg} 2 p$ & 48.4 & $\mathrm{Mg}$ & 13.0 \\
\hline \multirow[t]{4}{*}{$\mathrm{Al}_{2} \mathrm{O}_{3-210}$} & $01 \mathrm{~s}$ & 527.6 & 0 & 26.2 \\
\hline & C 1s & 283.5 & C & 59.0 \\
\hline & $\mathrm{Al} 2 \mathrm{~s}$ & 118.7 & $\mathrm{Al}$ & 1.8 \\
\hline & $\operatorname{Mg} 2 p$ & 49.9 & $\mathrm{Mg}$ & 13.0 \\
\hline
\end{tabular}


The amount of sulphur at the surface in the sample $S Z_{\text {fresh }}$ is $15 \%$, and the amount of sulphur in the samples $S Z_{170}$, $\mathrm{SZ}_{190}$ and $\mathrm{SZ}_{210}$, is $0.1,0.7$ and 0.7 , respectively. For the sample $\mathrm{SZ}_{\text {reused }}$ there was no measurable sulphur traces. It is inferred from Tables 5 and 6 that there is leaching of the acid sites of both alumina and SZ. This means that the acid sites found in the fresh sample have leached out into the aqueous solution under the reaction conditions presented in this paper. It is also shown that the atomic concentration of $C$ is lower on the surface of the fresh sample (29\%) than the atomic concentration of $\mathrm{C}$ on the spent samples $\mathrm{SZ}_{170}(76 \%), \mathrm{SZ}_{190}(67 \%), \mathrm{SZ}_{210}(61 \%)$ and $\mathrm{SZ}_{\text {reused }}(49 \%)$. This means that there is carbon deposition on the surface of the catalyst after hydrothermal reaction, in accordance to the humins imaged by SEM (Figures 7c and 7d).

The sample of $\mathrm{Al}_{2} \mathrm{O}_{3 \text { fresh }}$ contains a lower $\mathrm{C}$ amount (24\%) than the sample $\mathrm{Al}_{2} \mathrm{O}_{3-210}$ after hydrothermal reaction (59\%). This also evidences the formation of carbon deposits on the surface (Figures $6 c$ and $6 d$ ) of the catalyst after hydrothermal reaction.

Table A6 shows the binding energy and the atomic concentration percentages of Nafion NR40 before and after hydrothermal reaction at $210{ }^{\circ} \mathrm{C}$, and Amberlyst DT before and after hydrothermal reaction at $170{ }^{\circ} \mathrm{C}$. Under those conditions, both catalysts suffer a sulphur loss. In addition, Amberlyst DT loses $\mathrm{Cl}$ and Nafion NR 40 loses F. Hence, leaching of acid sites under these conditions was seen from all solid acid catalysts tested.

In the dehydration of xylose, the degradation of acid concentration, the leaching of $S$ and the accumulation of byproducts are the main factors that cause the deactivation of the catalyst. The results shown in Tables 5 and 6 from samples $\mathrm{SZ}$ and $\mathrm{Al}_{2} \mathrm{O}_{3}$ before and after hydrothermal reaction correlate with the catalytic activity tests in Figure 1 and 2 and the models shown in Figures 3-5. Under the above-mentioned experimental conditions FUR, once it is formed, it decomposes as well as the xylose. The decomposition products evolve forming humins on the surface of the catalysts (Figure 6 and 7), which is obviously detrimental to the reaction. 


\subsection{Reusability}

The stability of the SZ on cordierite under reaction conditions was investigated by employing this catalyst in a series of xylose dehydration reactions. Prior to each cycle, the SZ on cordierite was washed with deionized water and dried at $105{ }^{\circ} \mathrm{C}$. Figure 8 shows five consecutive reaction runs of $\mathrm{SZ}$ on cordierite at $190{ }^{\circ} \mathrm{C}$ in $9 \mathrm{~min}$. After this, the catalyst was washed, dried at $105^{\circ} \mathrm{C}$, calcined and impregnated again with $1 \mathrm{M} \mathrm{H}_{2} \mathrm{SO}_{4}$ (cycle 6).

After 5 cycles, the catalytic activity of the reused catalyst decreased from $38 \%$ to $7 \%$, as well as the conversion of xylose (from $97 \%$ to $37 \%$ ). At the same time, the activity of the catalyst can be recovered by calcination and a FUR yield of $39 \%$ is obtained again. These results are in accordance with the XPS results, since the catalytic activity of the reused catalysts decreased in each cycle without regeneration. This result indicates that the observed progressive catalyst deactivation might be related to the accumulation of insoluble organic matter, which could be blocking the surface of the catalyst, hence leading to disabled acid sites. The catalyst deactivation includes also leaching of the active sites (Table 6).

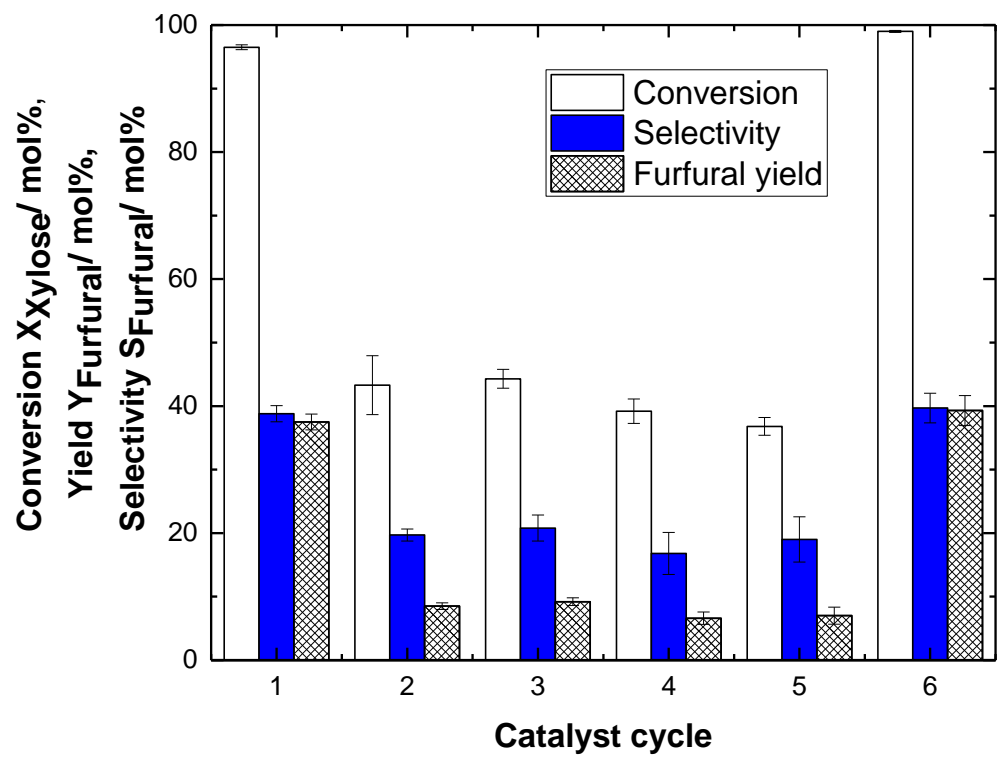

Figure 8. Reusability of SZ on cordierite for the dehydration of xylose to FUR using $50 \mathrm{mg}$ of catalyst at $190{ }^{\circ} \mathrm{C}$ for 9 min (xylose conversion (white bar), FUR yield (blue bar) and selectivity to FUR (striped bar)). 


\section{Conclusions}

A kinetic model for the auto-catalyzed and solid acid-catalyzed decomposition of xylose using $\mathrm{SZ}_{2} \mathrm{Al}_{2} \mathrm{O}_{3}$ on cordierite and Nafion NR40 at temperatures from 170 to $210{ }^{\circ} \mathrm{C}$ in aqueous phase was developed. Reaction rate constants for xylose and FUR decomposition were also determined in the temperature range of 170 to $210{ }^{\circ} \mathrm{C}$. The major product of auto-catalyzed and solid acid-catalyzed xylose dehydration was FUR, the maximum mole fraction yield of which was $49 \%$ in $60 \mathrm{~min}$ at $210{ }^{\circ} \mathrm{C}$. When using SZ on cordierite, the fastest time to reach the maximum mole fraction yield (41\%) was in $2 \mathrm{~min}$ (at $210^{\circ} \mathrm{C}$ ). When adding $\mathrm{Al}_{2} \mathrm{O}_{3}$, the fastest time to reach the maximum mole fraction yield (43\%) was in $30 \mathrm{~min}$ (at $210^{\circ} \mathrm{C}$ ). When adding Nafion NR40 and Amberlyst DT, the maximum mole fraction yield of FUR was $41 \%$ in $8 \mathrm{~min}$ at $210^{\circ} \mathrm{C}$ and $30 \%$ in $60 \mathrm{~min}$ at $170{ }^{\circ} \mathrm{C}$, respectively. Under the experimental conditions used, leaching of S, F, Cl was evidenced from SZ, Nafion NR40 and Amberlyst DT, respectively. Besides, the acid site density of spent samples shows lower values than those of fresh catalysts. It was also seen deposition of $\mathrm{C}$ on the surface of samples after hydrothermal reaction, which means that humins were formed on the solid acid catalysts, affecting the solid acid catalysts' performance.

There was no xylulose formation detected under auto-catalyzed conditions, xylulose was only formed when adding $\mathrm{SZ}$ and $\mathrm{Al}_{2} \mathrm{O}_{3}$. This could be due to the presence of Lewis acid sites contained in the solid acid catalysts.

Overall, hydrothermal stability should be further improved, as well as their acid site density. In addition, it is crucial to avoid the decomposition of FUR once it is formed, either by a secondary process such as nitrogenstripping or on-site extraction systems such as organic solvents included in a bi-phasic set-up.

\section{Acknowledgements}

This research has been done in collaboration with Stora Enso and funded through Erasmus Mundus Joint Doctoral Programme SELECT+, the support of which is gratefully acknowledged. G.G.M. was supported also by CIMO (Centre for International Mobility Finland) and by CONACYT (the Mexican National Council of Science and Technology). The authors are also grateful for the support of the staff at the Department of Bioproducts and Biosystems at Aalto University and the Institute of Energy Technologies in the Technical University of Catalonia, 
especially to Rita Hatakka (at Aalto University), Albert Casanovas and Lluís Soler (at UPC). Satu Ojala supported this research with $\mathrm{NH}_{3}$-TPD analysis at the University of Oulu, Finland.

References

[1] J. Chheda, G. Huber and J. Dumesic, Angewandte Chemie International Edition 46 (2007) 7164-7183.

[2] R. Weingarten, J. Cho, J. Conner Wm.Curtis and G.W. Huber, Green Chem. 12 (2010) 1423-1429.

[3] J. Carlos Serrano-Ruiz and J.A. Dumesic, Green Chem. 11 (2009) 1101-1104.

[4] AnonymousSugar Series 13 (2000) 98-103.

[5] L. Yang, J. Su, S. Carl, J.G. Lynam, X. Yang and H. Lin, Applied Catalysis B: Environmental 162 (2015) 149-157.

[6] A.S. Mamman, J. Lee, Y. Kim, I.T. Hwang, N. Park, Y.K. Hwang, J. Chang and J. Hwang, Biofuels, Bioproducts and Biorefining 2 (2008) 438-454.

[7] C. Moreau, R. Durand, D. Peyron, J. Duhamet and P. Rivalier, Industrial Crops and Products 7 (1998) 95-99.

[8] R. O'Neill, M.N. Ahmad, L. Vanoye and F. Aiouache, Ind Eng Chem Res 48 (2009) 4300-4306.

[9] R. Sahu and P.L. Dhepe, ChemSusChem 5 (2012) 751-761.

[10] S. Lima, A. Fernandes, M.M. Antunes, M. Pillinger, F. Ribeiro and A.A. Valente, Catalysis Letters 135 (2010) 41-47.

[11] S. Lima, M.M. Antunes, A. Fernandes, M. Pillinger, M.F. Ribeiro and A.A. Valente, Applied Catalysis A: General 388 (2010) 141-148. 
[12] R. Weingarten, G.A. Tompsett, W.C. Conner Jr. and G.W. Huber, Journal of Catalysis 279 (2011) 174-182.

[13] L.R. Ferreira, S. Lima, P. Neves, M.M. Antunes, S.M. Rocha, M. Pillinger, I. Portugal and A.A. Valente, Chem. Eng. J. 215-216 (2013) 772-783.

[14] E.I. Gürbüz, J.M.R. Gallo, D.M. Alonso, S.G. Wettstein, W.Y. Lim and J.A. Dumesic, Angewandte Chemie International Edition 52 (2013) 1270-1274.

[15] A. Yepez, A. Garcia, M.S. Climent, A.A. Romero and R. Luque, Catal. Sci. Technol. 4 (2014) 428-434.

[16] M.J.C. Molina, M.L. Granados, A. Gervasini and P. Carniti, Catalysis Today 254 (2015) 90-98.

[17] G.H. Jeong, E.G. Kim, S.B. Kim, E.D. Park and S.W. Kim, Microporous and Mesoporous Materials 144 (2011) 134-139.

[18] S. Kaiprommarat, S. Kongparakul, P. Reubroycharoen, G. Guan and C. Samart, Fuel 174 (2016) 189-196.

[19] I. Agirrezabal-Telleria, J. Requies, M.B. Güemez and P.L. Arias, Applied Catalysis B: Environmental 115-116 (2012) 169-178.

[20] I. Agirrezabal-Telleria, C. García-Sancho, P. Maireles-Torres and P.L. Arias, Chinese Journal of Catalysis 34 (2013) 1402-1406.

[21] I. Agirrezabal-Telleria, J. Requies, M.B. Güemez and P.L. Arias, Applied Catalysis B: Environmental 145 (2014) 34-42.

[22] P. Bhaumik, T. Kane and P.L. Dhepe, Catal. Sci. Technol. 4 (2014) 2904-2907.

[23] A.S. Dias, M. Pillinger and A.A. Valente, Journal of Catalysis 229 (2005) 414-423.

[24] H. Li, A. Deng, J. Ren, C. Liu, W. Wang, F. Peng and R. Sun, Catalysis Today 234 (2014) 251-256. 
[25] S. Lima, M. Pillinger and A.A. Valente, Catalysis Communications 9 (2008) 2144-2148.

[26] E. Lam, J.H. Chong, E. Majid, Y. Liu, S. Hrapovic, A.C.W. Leung and J.H.T. Luong, Carbon 50 (2012) 1033-1043.

[27] A.S. Dias, M. Pillinger and A.A. Valente, Applied Catalysis A: General 285 (2005) 126-131.

[28] A.S. Dias, M. Pillinger and A.A. Valente, Microporous and Mesoporous Materials 94 (2006) 214-225.

[29] A.S. Dias, S. Lima, M. Pillinger and A.A. Valente, Catalysis Letters 114 (2007) 151-160.

[30] E. Sairanen, K. Vilonen, R. Karinen and J. Lehtonen, Topics in Catalysis 56 (2013) 512-521.

[31] E. Lam, E. Majid, A.C.W. Leung, J.H. Chong, K.A. Mahmoud and J.H.T. Luong, ChemSusChem 4 (2011) 535-541.

[32] I. Agirrezabal-Telleria, A. Larreategui, J. Requies, M.B. Güemez and P.L. Arias, Bioresour. Technol. 102 (2011) 7478-7485.

[33] A.S. Dias, S. Lima, M. Pillinger and A.A. Valente, Carbohydrate Research 341 (2006) 2946-2953.

[34] S. Verma, R.B.N. Baig, M.N. Nadagouda, C. Len and R.S. Varma, Green Chem. 19 (2017) 164-168.

[35] V. Choudhary, S.I. Sandler and D.G. Vlachos, ACS Catal. 2 (2012) 2022-2028.

[36] O. Ershova, J. Kanervo, S. Hellsten and H. Sixta, RSC Adv. 5 (2015) 66727-66737.

[37] B. Saez, A. Santana, E. Ramírez, J. Maçaira, C. Ledesma, J. Llorca and M.A. Larrayoz, Energy Fuels 28 (2014) $6006-6011$.

[38] C. Ledesma and J. Llorca, Chem. Eng. J. 154 (2009) 281-286.

[39] O. Ershova, K. Nieminen and H. Sixta, ChemCatChem 9 (2017) 3031-3040. 
[40] M.A. Mellmer, C. Sener, J.M.R. Gallo, J.S. Luterbacher, D.M. Alonso and J.A. Dumesic, Angewandte Chemie International Edition 53 (2014) 11872-11875.

[41] B. Danon, G. Marcotullio and W. de Jong, Green Chem. 16 (2014) 39-54.

[42] K. Lamminpää, J. Ahola and J. Tanskanen, Bioresour. Technol. 177 (2015) 94-101.

[43] N. Akiya and P.E. Savage, Chem. Rev. 102 (2002) 2725-2750.

[44] Z. Chen, W. Zhang, J. Xu and P. Li, Chin. J. Chem. Eng. 23 (2015) 659-666.

[45] B. Danon, W. Hongsiri, L. van der Aa and W. de Jong, Biomass Bioenergy 66 (2014) 364-370.

[46] I. van Zandvoort, Y. Wang, C.B. Rasrendra, E.R.H. van Eck, P.C.A. Bruijnincx, H.J. Heeres and B.M. Weckhuysen, ChemSusChem 6 (2013) 1745-1758.

[47] C. Sievers, I. Musin, T. Marzialetti, M. Valenzuela?Olarte, P. Agrawal and C. Jones, ChemSusChem 2 (2009) 665-671.

[48] K.J. Zeitsch, Sugar Series 13 (2000) 317-318.

[49] Y. Yang, C. Hu and M.M. Abu-Omar, ChemSusChem 5 (2012) 405-410.

[50] J.B. Binder, J.J. Blank, A.V. Cefali and R.T. Raines, ChemSusChem 3 (2010) 1268-1272.

[51] J. Iglesias, J.A. Melero, G. Morales, M. Paniagua and B. Hernández, ChemCatChem 8 (2016) 2089-2099.

[52] M. Paniagua, S. Saravanamurugan, M. Melian-Rodriguez, J.A. Melero and A. Riisager, ChemSusChem 8 (2015) 1088-1094. 
[53] M.G. Mazzotta, D. Gupta, B. Saha, A.K. Patra, A. Bhaumik and M.M. Abu-Omar, ChemSusChem 7 (2014) 23422350.

[54] G.D. Yadav and J.J. Nair, Microporous and Mesoporous Materials 33 (1999) 1-48.

[55] B.T. Loveless, A. Gyanani and D.S. Muggli, Applied Catalysis B: Environmental 84 (2008) 591-597.

[56] G.G. Volkova, S.I. Reshetnikov, L.N. Shkuratova, A.A. Budneva and E.A. Paukshtis, Chemical Engineering Journal 134 (2007) 106-110.

[57] L. Filiciotto, A.M. Balu, J.C. Van der Waal and R. Luque, Catalysis Today In Press (2017) .

[58] V. Choudhary, A.B. Pinar, S.I. Sandler, D.G. Vlachos and R.F. Lobo, ACS Catal. 1 (2011) 1724-1728.

[59] S.J. You, Y.T. Kim and E.D. Park, Reaction Kinetics, Mechanisms and Catalysis 111 (2014) 521-534.

[60] S. Lima, M.M. Antunes, A. Fernandes, M. Pillinger, M.F. Ribeiro and A.A. Valente, Applied Catalysis A: General 388 (2010) 141-148.

[61] S.B. Kim, M.R. Lee, E.D. Park, S.M. Lee, H. Lee, K.H. Park and M. Park, Reaction Kinetics, Mechanisms and Catalysis 103 (2011) 267-277.

[62] P.J. Oefner, A.H. Lanziner, G. Bonn and O. Bobleter, Monatshefte für Chemie / Chemical Monthly 123 (1992) 547-556.

[63] Q. Jing and X. Lü, Chinese Journal of Chemical Engineering 15 (2007) 666-669.

[64] K. Lamminpää, J. Ahola and J. Tanskanen, Ind Eng Chem Res 51 (2012) 6297-6303.

[65] T.M. Aida, N. Shiraishi, M. Kubo, M. Watanabe and R.L. Smith Jr., The Journal of Supercritical Fluids 55 (2010) 208-216. 
[66] M. Al-Hazmi and A.W. Apblett, Catal. Sci. Technol. 1 (2011) 621-630.

[67] A. Casanovas, C. de Leitenburg, A. Trovarelli and J. Llorca, Catalysis Today 138 (2008) 187-192.

[69] R. Karinen, K. Vilonen and M. Niemelä, ChemSusChem 4 (2011) 1002-1016.

[70] Y. Wang, K. Lee, S. Choi, J. Liu, L. Wang and C.H.F. Peden, Green Chem. 9 (2007) 540-544.

[71] H. Yang, R. Lu, J. Zhao, X. Yang, L. Shen and Z. Wang, Mater. Chem. Phys. 80 (2003) 68-72.

[72] M. Haneda, K. Takamura, Y. Doi, N. Bion and L. Vivier, J. Mater. Sci. 52 (2017) 5835-5845.

[73] S.L. Goertzen, K.D. Thériault, A.M. Oickle, A.C. Tarasuk and H.A. Andreas, Carbon 48 (2010) 1252-1261. 